\title{
Postulados éticos para una didáctica ecologista en el aula. Frente al escepticismo ecológico, responsabilidad educativa, responsabilidad política
}

\author{
José Antonio Mérida Donoso \\ Departamento de Didácticas Específicas, Área de Didáctica de las Ciencias Sociales, \\ Universidad de Zaragoza. España. jamerida@unizar.es \\ ORCID: https://orcid.org/0000-0001-7385-6772
}

[Recibido: 9 octubre 2020. Revisado: 20 enero 2021. Aceptado: 5 abril 2021]

\begin{abstract}
Resumen: La crisis ecológica que asola la sociedad, evidenciada más si cabe por el covid-19, exige de una mayor concienciación y crítica por parte de la ciudadanía, capaz de comprender y oponerse a la lógica moderna que ha producido pandemia, desde la forma de relación entre la especie humana y la naturaleza, hasta los patrones de correspondencia que mantenemos entre nosotros. Frente a la connivencia del modelo de producción capitalista, este artículo pretende adentrarse en la lógica del escepticismo climático, abordar su crítica y subrayar la necesidad de mitigarlo desde una educación que, acorde a los derechos humanos, permita una ciudadanía crítica. Una propuesta que implica pasar de la concienciación y empatía con las generaciones venideras a la crítica del sistema capitalista y, finalmente, a una acción educativa abierta, capaz de abarcar distintos modelos como el ecofeminismo.
\end{abstract}

Palabras clave: responsabilidad política; educación para la sostenibilidad; negacionismo ecológico; escepticismo ambiental; formación de educadores.

Ethical postulates for an ecologist didactics in the classroom. Against "ecological skepticism": an educational responsibility, political responsibility

\begin{abstract}
The ecological crisis that plagues society, further evidenced by the covid 19 demand for greater awareness and criticism by citizens, capable of understanding and opposing the modern logic that has produced a pandemic, from the form of relationship between the human species and nature down to the patterns of correspondence between us. Faced with the concomitance of the capitalist production model, this article aims to delve into the logic of skepticism of climate change to address its criticism and demonstrate the need for training. A proposal that implies moving from awareness and empathy with future generations to criticism of the capitalist system and, finally, to an open educational action, capable of encompassing different models such as ecofeminism.
\end{abstract}

Keywords: political responsibility; education for sustainibality; ecological negationism; environmental skepticism; training of educators.

Para citar este artículo: Mérida Donoso, J. A. (2021) Postulados éticos para una didáctica ecologista en el aula. Frente al escepticismo ecológico, responsabilidad educativa, responsabilidad política. Revista de Educación Ambiental y Sostenibilidad 3(1), $1101 . \quad$ doi: 10.25267/Rev_educ_ambient_sostenibilidad.2021.v3.i1.1101

\section{Introducción. El "anfiteatro humano" de la competitividad}

A poco que se siga mínimamente cualquier medio de comunicación se advierte que, al margen de las perspectivas "negacionistas" capitaneadas por Donald Trump, se está generando un cambio en la distribución de los patrones meteorológicos (Björnberg et al. 2017). En efecto, aunque la negación del cambio climático antropogénico propaga la imposibilidad de toda alternativa posible, la realidad ambiental que asola nuestro mundo indica todo lo contrario. Así, aunque el cambio climático es ya uno de los temas más importantes, transversales y compartidos de la agenda global, la lógica del 
capitalismo impone nuevas apariencias. Si antes se pretendía negar el cambio climático, ahora, ante la evidencia del mismo, se relativiza el daño causado por las actividades humanas por lo que se niega la necesidad de cambiar políticas de producción (Boussalis y Coan, 2016; Brulle, 2014; Farrell, 2016). Para ello, se intenta sostener que la acumulación en la atmósfera de gases de efecto invernadero provocados por la acción del ser humano a través de la deforestación o el uso de determinados productos químicos y combustibles fósiles no se vincula a los cambios ambientales y, en caso de que se acabe por aceptar esta relación, la relación causaefecto sería mínima. Se trata, en suma, de una transformación retórica del mismo paradigma, que pasa del negacionismo al escepticismo. Fue Lomborg (2004) quién popularizaría el término al relativizar las relaciones causa efecto que mantienen la mayoría de los científicos, al mismo tiempo que se sustentaba como axioma que los cambios se vinculan a una etapa más de nuestro planeta y, por tanto, es algo natural, desvinculándolos de la acción del ser humano. Una perspectiva que cuestionaba el discurso académico y objetaba sus estadísticas, pero que era incapaz de cuestionarse y objetar estadísticas propias, presentándose como incuestionables al ser incapaz de relativizar sus propios postulados (Laursen, 2009).

Para combatirlo, más allá de la comunidad científica que lo desacredita, la sociedad tiene la responsabilidad de formarse, para poder establecer comportamientos más respetuosos con el medio ambiente. En este marco, la educación supone un resorte fundamental para fomentar una crítica estructural desde su comprensión, análisis y tratamiento y capacitar a la ciudadanía a derribar los nuevos modelos negacionistas de intereses crematísticos erigidos entorno al modelo ético del «homo economicus» en la lucha por la vida y la ganancia personal. Solo mediante una Educación Ambiental integral en todo el sistema educativo se podrá adquirir una concepción integrada de los procesos históricos, económicos, tecnológicos, políticos y culturales de la crisis ecológica y contextualizar el negacionismo con la manera de entender nuestra relación con el mundo (Latour, 2017).

Así pues, en el siguiente artículo se analizan las motivaciones del negacionismo como oposición a una ética ecológica para subrayar la necesidad de mitigarlo desde una educación acorde a los derechos humanos, formadora de estudiantes capaces de identificar sus emociones y orientarlas desde un desarrollo crítico y ético. Se entabla así un paralelismo entre responsabilidad política y educativa, al entender que, así como es inviable un gobierno neutro -obviar esta crisis supone en sí un posicionamiento ideológico- también lo es una educación aséptica. Se considera pues que la concepción de desarrollo sostenible supone una perspectiva ideológica que debe ser desentrañada por la educación, ya que esta, igual que cualquier partido político e institución económica o empresa, tanto a nivel nacional como supranacional, debería formar y capacitar para mantener una adecuada política de prevención, protección y promoción. Ideología que, en última instancia, entronca con los derechos humanos ya que el derecho al ambiente sin riesgos, limpio, saludable y sostenible forma parte de los derechos económicos, sociales y culturales y refuerza y complementa los derechos civiles y políticos, siendo universalmente reconocidos en el marco teórico y fundados sobre fuentes jurídicas internacionales. 


\section{La dialéctica del negacionismo}

Todo avance hacia un cambio en el paradigma de desarrollo que discurra paralelo a una sostenibilidad medioambiental siempre despertará el rechazo de los sectores económicos y políticos que sientan sus intereses vulnerados (McCright y Dunlap, 2011). Así se explica el empeño de Donald Trump por desarticular la apuntada relación entre acción humana y cambio climático, así como la proliferación de partidos extremistas y tendencias abiertamente neoliberales que atraviesan Europa y Latinoamérica defendiendo una misma idea: todo ecologismo es extremista. Su argumentación se basa, por un lado, en el desprestigio y politización del aval científico al enmarcarlo como un ataque a la libertad económica al pretender guiar las políticas que gobiernan las relaciones entre el medio ambiente y la economía (Bohr, 2016) y, por otro, en promocionar otra perspectiva supuestamente científica que sustente posturas negacionistas. En efecto, a pesar de que gran parte del mundo reconoce la necesidad de una acción inmediata, todavía hay quienes cuestionan el consenso científico sobre el cambio climático y desalientan los esfuerzos para abordarlo. Destaca, en este sentido, el rechazo al consenso científico que defiende el Heartland Institute, en cuyas investigaciones se afirma que los costos económicos de tratar de mitigar el cambio climático pueden exceder los beneficios (Bast, 2010). Las distintas argumentaciones esgrimidas por el negacionismo van desde la negación, la minimización del cambio o su aceptación, pero excluyendo causas humanas, hasta la apelación a intereses considerados más altos como sería el progreso económico, la pretendida tergiversación de los científicos y la manipulación de los ambientalistas (Dunlap y McCright, 2010). En estos últimos aspectos, esta ideología tiende a descalificar, cuando no a ridiculizar, toda lucha contra el cambio climático, tildándolos de radicales beligerantes o ecohistéricos (Bendfeldt, 1996). En cualquier caso, todas estas estrategias tendrían un mismo denominador común: rehusar responsabilidades.

A su vez, esta ideología se ampara en la falta de perspectivas estructurales que posibilitan la creencia de que los problemas ecológicos son más una consecuencia no deseada de toma de decisiones erradas, que de un modo de vida basado en el consumo y enriquecimiento propio del capitalismo voraz (Bliuc et al. 2015). Así, ante la posibilidad de un cambio que pueda suponer la pérdida de poder de las élites, la dialéctica de "negar lo innegable" se aboga por un mantenimiento de los privilegios imperecedera o, en su defecto, un status quo en los no estén en cuestión (Collomb, 2014). En cualquier caso, frente al pretendido paréntesis que supone el negacionismo, lo cierto es que múltiples ecologistas y científicos, movimientos y asociaciones han intentado incrementar la concienciación social sobre la sostenibilidad desde hace décadas. Sin embargo, llama la atención el número relativamente pequeño de artículos que abordan la negación organizada, iniciada y perpetuada por gobiernos, incluidos jefes de estado y ministros de gobierno (Björnberg et al. 2017) ante la influencia de estos discursos en la sociedad (Colomb, 2014) y su capacidad retórica de aparentar tener un corpus estructurado (Dunlap y McCright, 2011).

\section{La dialéctica de una sociedad crítica y concienciada}

Tras los datos desvelados por el informe Los límites del crecimiento de Meadows et al. (1972) y al calor de la proliferación de grupos ambientalistas o ecologistas, la sociedad ha ido incrementando su inquietud tal y como se plasma en la mayor presión 
que ejerce sobre la política. De esta suerte, a medida que se han evidenciado las trágicas consecuencias de entender el planeta como fuente de recursos ilimitados, el murmullo de los negacionistas ha ido creciendo, y se ha plasmado en la ausencia políticas estructurales que engloben medidas económicas y fiscales, forestales y de empleo (Baigorri y Caballero, 2018). Al mismo tiempo, la sobreexposición e instrumentalización por parte de medios de comunicación, instituciones y partidos políticos (Boykoff, 2013), así como la desinformación ha permitido que términos como ecologismo y medio ambiente se hayan vaciado, en parte, de su contenido, a modo de significantes sin significado, dispuestos como banderas vacías para ser reelaboradas y ondeadas por el mejor demagogo. En consecuencia, mientras los partidos políticos han hecho uso y abuso del medio ambiente como baza electoral, se ha dejado una estela de promesas vagas, en paralelo con el mero papel mojado en que parecen haberse convertido las grandes declaraciones como la del Medio Ambiente y el Desarrollo de Río en 1992 así como sus constantes apéndices. En definitiva, el fracaso en la puesta en práctica de los distintos acuerdos y conferencias, evidencia que solo el empoderamiento de la ciudadanía podrá desembocar en una verdadera transformación.

\section{Antecedentes y fundamentación teórica: responsabilidades políticas y educativas}

Más allá del impacto de las inversiones internacionales y el comercio mundial en el medio ambiente, no cabe duda de que son los mercados financieros los que imposibilitan un cambio en el paradigma capitalista. Como apunta Arrighi (2007) son las divisas y su mercado -y no los derechos- las que hacen que el mundo sea global. Se trata de una visión economicista, en la que la globalización cultural vendría a configurar una superestructura sustentada sobre un capitalismo ávido del máximo beneficio, pero incapaz de pensar en sus consecuencias. Frente a esta visión, el ecologismo entronca con los derechos humanos, al recordarnos que la responsabilidad de todo individuo con su entorno y medio ambiente no empieza y acaba con el reciclaje, sino con el consumo. En efecto, la sostenibilidad se vertebra en torno a la necesidad de un consumo individual y comunal acorde a necesidades reales, que exige ciertas garantías políticas y un acercamiento a posturas científicas con las que poder concienciar a la sociedad. En contraposición, se instaura el discurso de la antirreflexión (McCright y Dunlap, 2010) en la medida en que ataca a dos elementos clave de la modernización reflexiva: el movimiento ambiental y la ciencia. Por su parte, gran parte de las investigaciones medioambientales obvian el impacto provocado por el estilo de vida (Christensen, 1997), cuando no socavan la dimensión material de las prácticas sociales, esto es, el comportamiento de la sociedad en su consumo cotidiano (Brand, 2010).

Así pues, en el campo académico y educativo se evidencia la necesidad de afianzar una suerte de proselitismo medioambiental que permita analizar críticamente las acciones de los diferentes actores y sus relaciones, dependencias e influencias con el medio ambiente y con los distintos recursos naturales. Y es que precisamente, cuando más se intentan anular cosmovisiones que aúnan cultura y naturaleza, es cuando se hace más necesario implementar perspectivas críticas comprometidas en la acción individual. Una petición recogida en el campo académico a través de una larga trayectoria que se remonta a los trabajos ya clásicos como los de Osborn (1948), 
Sauer (1956) o Sacristán (2009), quienes señalaron no solo esa responsabilidad individual, sino también la estatal y, por ende, la de los gobernantes a la hora de gestionar el espacio en el que convivimos. Se trata de la necesidad de equiparar el derecho positivo a los derechos humanos para garantizar un equilibrio con la naturaleza en el marco del estado de derecho, homologando la gobernabilidad "a una categoría constituyente, refundacional del poder político" (Roitman 2000, p. 28). Todo un cuestionamiento a la lógica del mercado que pone en jaque un juego de relaciones no recíproco, para velar por una correspondencia conforme a tres estadios de valores e ideales: humanismo, productividad y ecología.

En estos tres ejes se inscribe una ética, la cual, según Ferrater Mora en su Diccionario de Filosofía, deriva de etos, que significa "costumbre" de ahí que, con frecuencia, se haya definido la ética como la doctrina de las costumbres. En este sentido, la Educación Ambiental, intrínsecamente unida al ecologismo, trasluce una ética que advierte sobre los problemas de nuestro planeta, busca soluciones y trata de frenar el avance de la degradación del medio. Por su parte, en la evolución del vocablo desde Aristóteles, este se ha ido identificando cada vez más con lo moral mientras se postulaba como el arte del buen vivir. En este marco se instaura el sistema filosófico desarrollado por Ayn Rand conforme a la defensa del propósito moral del ser humano, el cual yace reducido a una búsqueda de su "interés propio racional", esto es, la propia felicidad. Una felicidad propia de un capitalismo puro o capitalismo laissez-faire que se hará patente conforme más se pueda consumir y se consuma (Etxebarria, 2004). Se trata de la sociedad idólatra del tener, el homo consumens que vive, habita y transforma la sociedad para hacer del consumo compulsivo su único fin (Fromm, 2013). Una percepción tecnoeconómica que, más que ignorar las actividades no remuneradas, desprecia todo aquello que no es calculable o medible (Benería, 1999).

Este capitalismo genera una superestructura cultural que, incapaz de cuestionarse, critica todo atisbo ecológico como atentado que supone contra la cultura, industria, tecnología y, en definitiva, la forma de vivir que propaga. A su vez, esta concepción se sustenta bajo dos pilares contrapuestos, a saber, que toda relación que establezca el ser humano con la naturaleza ha de ser violenta y que los problemas de sostenibilidad no son sistémicos $y$, por tanto, son ajenos al capitalismo. Se invalida así la extrapolación de esta realidad, negando toda posible política ecológica, así como la acción transformadora individual y colectiva, limitando la crisis medioambiental a un problema científico-tecnológico. Dicho de otro modo, no solo se capitaliza la ciencia, sino que se niega la responsabilidad ética, supeditándola a los intereses del capitalismo. Esto es, a la única ética posible: la suya, la ley del "más fuerte", precisamente el único sistema económico que carece de un código moral propio y específico. Esta "anorexia moral" se fundamenta en una suerte de juego de suma cero en el que para que uno gane otro tiene que perder.

Asimismo, dado que todo código moral supone poner límites a la acción humana, se evidencia la necesidad de romper esta lógica perversa de suma cero, para dejar de restar y empezar a sumar contra el Antropoceno. De lo contrario, el lesivo actuar de la especie humana seguirá imponiendo sus propias reglas (Mendivelso y Arias, 2015). Un cambio de esta inercia supondría pasar de la dependencia a la interdependencia, una transformación que implicaría que todos los participantes sean emocional, económica o moralmente "independientes" (Prebisch, 1988). Así pues, esta transformación se vincula inexorablemente a la necesidad de la reducción de la 
pobreza en otras zonas del planeta. De igual modo, interpela a la responsabilidad de todos los sujetos, excluyendo la pasividad como opción viable y abogando por una acción responsable desde la praxis configurada en nuestras idiosincrasias. Una inacción, por otra parte, instaurada en la sociedad conforme al "contramovimiento ambientalista" y su transformación discursiva desde la oposición a la alarma ambiental hasta un sutil silencio fraguado en la ausencia de toma de decisiones (McCright y Dunlap, 2010). En oposición a esta perspectiva, la mencionada transformación implica un cambio de los hábitos sociales y culturales aprendidos y, por tanto, modificables, con la consecuente disminución del consumo y el cimiento de una sociedad más igualitaria. Dicho de otra forma, la globalización no puede obviar o reutilizar conceptos como justicia social y desarrollo sostenible y viable, sin atender a proyectos que conjuguen el desarrollo económico con la satisfacción de las necesidades de la población mundial, de manera simétrica, que permita equilibrar la distribución de los recursos sin ponerlos en peligro.

Al ahondar en la asimetría social impuesta como modelo neoliberal y capitalista se aprecia que esta también se aplica en la tierra, como fuente de recursos, en tanto en cuanto una parte de la sociedad se hace cargo de ella e impone su explotación atendiendo a intereses capitalistas mediante un consumo apriorista. Este factor, a su vez, nos permite replantearnos ciertos movimientos poblacionales como ocurre en el interior de las fronteras brasileñas, donde en los denominados "pulmones del mundo", subyacen diversas migraciones ambientales ante la sobreexplotación de recursos naturales, propias de una sobre-urbanización con las consecuentes sequías, deforestación y pérdida de biodiversidad que acarrea. En este sentido, diversos movimientos sociales han apoyado una economía solidaria, poniendo de manifiesto la necesidad de un verdadero cambio de paradigma económico que sitúe en el centro de la economía la sostenibilidad de la vida, una vida que valga la pena ser vivida. Estos movimientos pueden servir como indicadores para buscar propuestas al servicio de las personas, que tengan como referencias prioritarias el medio ambiente, el desarrollo sostenible. Una perspectiva plausible tanto por la búsqueda de la participación de todas las personas de estos movimientos, sin discriminación y sin exclusiones, y la capacidad que tienen de destacar la interconexión entre los seres humanos, y entre estos y la naturaleza. En este contexto, los valores que promueven diversos movimientos sociales permiten fomentar las relaciones interhumanas, al amparo de la confianza, la cooperación, la solidaridad, y la acción de compartir. Así por ejemplo, y volviendo a Brasil, un país con una evidente desigualdad económica y alta concentración de propiedad de la tierra (Mérida 2018), necesitaría de una reforma agraria basada en los principios de cooperación, solidaridad y reciprocidad, en conexión con la tierra y con los principios de la vida, en oposición a los de competencia y avidez de lucro. Una ética de la complementariedad, la colectividad y el equilibrio enfrentada a una superestructura tan alejada de la solidaridad como supeditada al individualismo.

Por su parte, la ecología renueva el acercamiento ético-jurídico con la naturaleza, al dotarla de sujeto de derecho como crítica a la impunidad contra las acciones de explotación ambiental que, en esencia, no dejan de ser reflejo de una perspectiva ideológica capitalista que reduce al planeta a una mera fuente de recursos "inagotables". En el fondo, más allá de las diferencias entre las corrientes ecologistas, todas ellas parten de la necesidad de mantener perspectivas estructurales y seguir 
luchando por ellas cuando la concienciación social permite institucionalizar ciertas perspectivas. Así, aunque diversas conferencias de la ONU sobre cambio climático han permitido acuerdos en la disminución de la producción de carbono y de gases del efecto invernadero, no se dan planteamientos holísticos. La perspectiva siempre es la de conformarse con reducciones que permitan mitigar las emisiones de contaminantes, quedando invalidada en su ambición al no partir de un posible cambio de paradigma como si este fuera impensable e imposible de facto. De igual modo, el concepto de "deuda climática", los acuerdos supraestatales que abordan los transportes marítimos y aéreos o la "neutralidad climática" en el mercado de carbono iniciado por el Acuerdo de Kioto, parecen estar siempre limitados, ante la mordaza que impone la lógica del capitalismo financiero en general y de la especulación en particular.

La ecología deviene así un instrumento de educación moral y reforma social. La asimetría normalizada -la que obliga a la competencia de todos contra todos, haciendo de la sociedad un "anfiteatro humano" en el que realizar las nuevas "luchas de gladiadores", con los aplausos y recompensas para los vencedores, y el escarnio y la humillación para los derrotados- es aplaudida por los pretendidos "herederos de la evolución natural". Esos que disfrutan de los privilegios y observan desde el palco que se aprovechan del "pesimismo escatológico" (McCarthy, 1992, p. 165), a modo de un escepticismo radical que impide la esperanza que supone todo intento de cambio, para perpetuarse. Para lograr este estancamiento la educación debe ser acrítica, de tal forma que su condición de fin en sí mismo y derecho inalienable desaparece para transformarse en una construcción de modelo social competitivo conforme al modelo de rentabilizar los recursos humanos formados.

Para acabar con esta inercia instaurada se necesita un cambio de paradigma ético, una vuelta a los planteamientos de "una escuela democrática" (Freire 2012, p. 122) abierta a la realidad contextual de los educandos, pero también dispuesta a aprender de sus relaciones con el contexto, donde las aulas no sean un recinto de lucha en el que prosperar o ser derrotado, sino espacios comprometidos con la búsqueda de la justicia, la ética y la moral (Schmelkes, 2002). Se trata pues de generar comunidades educativas en el aula, enfocadas a ampliar su autonomía y fomentar su integración y capacidad crítica. Solo poniendo la ética en un lugar capital de la vida humana y promoviendo la discusión y el debate en el seno de la sociedad será posible vivir adecuadamente en y con la naturaleza. De lo contrario, en el futuro se seguirá en el juego de inacción que sostiene el tablero de asimetrías, conforme a su única regla, la de la "cooperación interesada", para que, tanto a nivel nacional como internacional, la minoría que más tiene se siga beneficiando de los que menos tienen.

\section{La labor del docente}

La educación sobre el cambio climático como pilar fundamental para reorientar la enseñanza y el aprendizaje frente a la emergencia climática actual parece ampliamente establecida y aceptada (Tilbury y Mulà, 2009). Sin embargo, a pesar del amplio acuerdo entre expertos, ciudadanos, educadores y activistas sobre la necesidad de implementarla dentro de un conjunto de estrategias de prevención, mitigación y adaptación (Jickling, 2013) y garantizar una acción estratégica, en lugar de fragmentaria (Tilbury y Mulà, 2009), parece que hay poco consenso en las esferas pública, política y académica sobre qué prácticas abordar, quién debe llevarlas al aula 
y cómo afrontarlas para garantizar una Educación Ambiental adecuada y eficaz (Krasny y DuBois, 2019). En este sentido, no cabe duda de que antes de formar es necesario formarse en la cultura de la igualdad y de la sostenibilidad, y obtener perspectivas estructurales que permitan ofrecer alternativas justas y defendibles frente a políticas desarrollistas. En consecuencia, como primer aspecto podemos destacar la importancia en la formación que tienen que jugar las universidades y la plasmación en sus programaciones de estas necesidades formativas, con el fin de que el futuro educador adquiera ciertos conocimientos interdisciplinares que le permitan criticar la realidad y construir modelos de intervención. Así pues, para que el docente adquiera una práctica profesional coherente desde la comprensión del medio ambiente como un espacio socioambiental, personal o promocional para la comunidad, deberá, por un lado, formarse en las posibilidades de las tecnologías limpias y eficientes y, por otro, dotarlo de herramientas críticas. Una perspectiva que tiene que ser trazada en todos los niveles educativos, con la correspondiente adaptación curricular en el ámbito universitario y preuniversitario e incluso en la formación no reglada que esto implica.

Esta reivindicación evidencia que, aunque existen experiencias enriquecedoras vinculadas a la innovación curricular, siguen siendo muchos los procesos que mantienen perspectivas fragmentada de la realidad, con currículos afines a una Educación Ambiental ajustada a lo disciplinar (Niño y Romero, 2014). Un desafío familiar a los educadores e investigadores ambientales, cuya realidad se enmarca en un contexto complejo ya que, aunque la educación es el mejor medio para abordar los problemas socioecológicos, esta permanece socavada por fondos insuficientes y currículos sobrecargados y subvalorados (Jensen y Schnack, 2006; Stevenson, 2007; Bieler et al. 2018).

En cualquier caso, más allá de que muchos educadores confunden Educación Ambiental con ecología o viceversa (Toro, 2006), parece evidente que la información supone la condición necesaria para promover y hacer propios valores vinculados a comportamientos sostenibles que permitan interacciones responsables. En este contexto, más allá de las posibilidades y responsabilidad de otros agentes, la Educación Ambiental debe partir de sus fines para dirigirse a la apropiación y generación de conocimientos, al desarrollo de hábitos, habilidades y capacidades, y a la formación de valores que propicien cambios de pensamiento, de sentimientos y de comportamientos. Se trata de establecer nuevas formas de relación de los seres humanos con la naturaleza, de estos entre sí y con el resto de la sociedad. Esta formación se constituye en premisa para que la sociedad pueda contribuir a un desarrollo sostenible. Un eje vertebrador desde las asignaturas que abordan la ética, las ciencias sociales y las ciencias naturales, pero también desde otras como pueden ser Iniciación a la Actividad Emprendedora y Empresarial (IAEE) o Lengua y Literatura. Como eje transversal del conjunto de asignaturas, todo docente deberá conocer la necesidad y la urgencia de adoptar alternativas de decrecimiento y fomentar un verdadero cambio de paradigma económico que sitúe en el centro de la economía la sostenibilidad de la vida. Una vida que valga la pena ser vivida. Si la transversalidad representa un factor de integración de los campos del conocimiento y facilita una comprensión reflexiva, crítica e integral de la realidad, su enfoque en la dimensión ambiental como expresión de la orientación de las relaciones hombre-sociedadnaturaleza revelará la complejidad, unidad y multidimensionalidad del medio 
ambiente (Roque, 2003). Todo un entresijo ético, conceptual, metodológico y práctico respecto a la forma en que las personas interactúan entre ellas y con la naturaleza y a cómo asumen su vida en el seno de la relación medio ambiente-desarrollo. Para ello, el docente estimulará la cooperación y solidaridad en lugar de la competencia, y generará debates y reflexiones sobre posibles cambios en el paradigma económico capitalista que permitan medir el éxito social e individual con otros indicadores. Se trata de afianzar un cambio en la cultura del consumo que abarque los deseos del consumidor y sus hábitos, con el fin de reformular los sistemas de producción, energéticos y alimentarios en modelos de convivencia más justos. En consecuencia, el docente implementará una "democracia de base", participativa y autónoma conforme a los siguientes hitos y necesidades:

- La formación de circuitos locales de comercio basados en la proximidad de los productores $y$ consumidores $y$, en la medida de lo posible, el autoabastecimiento.

- Una mayor libertad individual frente al sistema de consumo dominante vigente.

- La urgencia de utilizar energías renovables y libres como mecanismo eficiente para alcanzar la emancipación de los ciudadanos.

- La concienciación en la acción individual y colectiva, como dos caras de una misma moneda, que hace de la ciudadanía el eje fundamental para una transformación social necesaria que permita combatir los problemas económicos y ecológicos existentes.

La suma de estos postulados fomentará una "ciudadanía verde" en formación y en acción. Una propuesta de interdependencia que invita a romper con el modelo del "yo" frente al "nosotros" (Mérida, 2019) y sustituirlo por uno de complementariedad equitativa que entiende el medio ambiente como patrimonio de la humanidad y, por tanto, elemento esencial de toda persona (Bryant y Bailey, 1997). La responsabilidad comunal demanda una crítica al modelo económico extractivo y, por tanto, una mayor formación en todos los ámbitos de la sociedad. De lo contrario, aunque siga manteniendo la imagen de buen funcionamiento, el capitalismo, como sistema devorador que es, de no menguar su voracidad, acabará por engullirse a sí mismo.

\section{El feminismo comunitario}

En esta, con el permiso de Gabo, "crónica de una muerte anunciada" a la que parecemos asistir, las posibilidades del ecofeminismo se evidencian. En efecto, como propuesta que busca expandirse y llegar especialmente a la población más excluida, así como movimiento crítico que amplia horizontes al no circunscribirse a roles de género, permite múltiples posibilidades en el ámbito educativo. En esencia, se trata de un movimiento que aúna el abuso que la naturaleza y el medio ambiente han recibido con el de las mujeres (Merchant, 1983). Así, por un lado, evidencia que, si las mujeres se cuentan entre las primeras víctimas del deterioro medioambiental, también son las protagonistas de la defensa de la naturaleza. Por otro, nos recuerda que el ecologismo, como oposición a la perspectiva unívoca del capitalismo, reivindica la historia, memoria e identidad de los pueblos sistemáticamente excluidos, esos que se quedaron sin voz en los relatos oficiales, para reconocer su legado y aprender de sus prácticas sociales y políticas, por lo general más participativas e incluyentes que las 
nuestras. Ambas corrientes, ecologismo y feminismo, cuestionan una mirada polarizada y jerarquizada, que antepone la priorización de la producción sobre la reproducción y de lo masculino sobre lo femenino mediante una violencia física y simbólica contra cuerpos y territorios.

En consecuencia, se adopta una perspectiva que, en su reconocimiento de la diversidad, parte de la premisa necesaria de superar todo tipo de dualismo. Su crítica hacia la confabulación del crecimiento ilimitado, la división laboral por sexos y la identidad individual pone de manifiesto cómo los mismos axiomas de los que presume el modelo liberal representativo son los mismos que obvian la ecodependencia y la interdependencia, los pilares fundamentales de la vida humana. Mitos que, a lo largo de la historia han permitido instrumentalizar a mujeres y ecosistemas, normalizando una serie de conductas que no son normales, por más habituales que sean, e invisibilizando toda realidad ajena al androcentrismo.

A su vez, el ecofeminismo ahonda por un lado en la idea de la construcción de economías locales solidarias, ecosuficientes y por otro, en la deconstrucción del dominio neoliberal, asimétrico y de género, en todas sus formas, evidenciando su versatilidad en diversos contextos educativos. En este marco, ofrece una alternativa real a la crisis de valores que atraviesa nuestra sociedad individualista. Las aportaciones del pensamiento crítico-feminista y ecologista permiten la confrontación al sexismo de la sociedad patriarcal y el androcentrismo de la dominación de tierra, esto es, al paradigma del ser conquistador, incapacitado para entender que el avance de la sociedad se fundamenta en la igualdad entre hombres y mujeres, en tanto partícipes no sólo de la economía, sino de la cultura y de la naturaleza.

Ciertamente, aunque el ecofeminismo sea tan vasto y variado como sus raíces feministas y ecológicas, no está exento de críticas, por esencializar la relación de la mujer con la naturaleza (Hatten-Flisher y Martusewicz, 2018). Sin embargo, ante las crisis ambientales y sociales globales que azotan el planeta, ofrece perspectivas pedagógicas para desarrollar respuestas efectivas a estas crisis interrelacionadas. Como tal, académicos de una variedad de disciplinas están revisando (y recuperando) el pensamiento ecofeminista (Turner, 2015). Se vinculan así distintos ejes (Martusewicz, Edmundson y Lupinacci, 2015) susceptibles de ser vinculados a la educación, a saber:

- Como posibilidad de modelo crítico ecológico-cultural de los discursos contemporáneos que monopolizan la visión del progreso.

- Como ética del cuidado y pedagogía de la responsabilidad.

- Como compromiso y análisis crítico del ecologismo, en sus aspectos epistemológicos y ontológicos, para desentrañar la relación entre el ser humano y el mundo que habita.

Así, el ecofeminismo permite un marco transversal que reconoce las raíces interconectadas del racismo, el sexismo y la pobreza con la degradación ecológica (Hatten-Flisher y Martusewicz, 2018). A su vez, propone una ética del cuidado entretejida para formar la base de una pedagogía de la responsabilidad que permita criticar los fundamentos culturales de la violencia e identificar prácticas y relaciones que ayuden a crear comunidades saludables y sostenibles, a la vez que genera sinergias entre individuos y comunidad. Una ética del cuidado como red de relaciones 
de responsabilidad y compromiso hacia el otro, esto es, como acción en forma de ayuda (Boff, 2004). Se trata en esencia, de generar propuestas que recojan puentes comunicativos confluyentes hacia una ética de igualdad y sostenibilidad. Toda una construcción conjunta y equilibrada entre personas y naturaleza que permita redefinir nuestra relación con la naturaleza, o lo que es lo mismo, una estrategia más para transformar la sociedad y la propia humanidad, haciéndola más humana.

Para llevar esta teoría al aula se pueden trazar análisis ecofeministas que muestren la afinidad mujer-naturaleza conforme a las concepciones polarizadas de la "naturaleza" (Li, 2007). Así, el ecofeminismo permite atender a las interconexiones entre varias formas de opresión, de tal forma que arroja luz sobre cómo la ideología de género influye en nuestra cosmovisión pudiendo enfatizar el activismo ético. Negar la posibilidad del ecologismo y del feminismo en la educación es desconocer sus posibilidades transformadoras. Este potencial renovador invita al profesorado a generar espacios de reflexión en el aula que ahonden en los motivos por los que las actividades "reproductivas", como la educación reciben un salario más bajo (Phillips y Rumens, 2016). Se trata, en definitiva, de reparar en la propia definición de "trabajo reproductivo", esto es, en aquellas actividades que no están dentro del alcance de los cálculos económicos convencionales tales como la atención infantil y de salud o las tareas domésticas. Unas tareas no remuneradas que a lo largo de la historia han recaído fundamentalmente sobre las mujeres (Finch, 1989) y que, por tanto, invitan a examinar las normas sociales y económicas existentes y a explorar posibilidades de restablecer normas para una comunidad global más justa. Una reparación a día de hoy más necesaria que nunca cuando, tal y como advierte Sandel (2020) el COVID-19 y los esfuerzos para contener su propagación han provocado un mayor volumen de trabajo de cuidados no remunerado. En consecuencia, según el autor, el número de cuidadoras pertenecientes a grupos étnicos minoritarios relegado a los márgenes de la sociedad crece constantemente con el subsiguiente incremento de su inseguridad económica e inestabilidad emocional, ante los problemas de ansiedad que acarrea la sobrecarga laboral. Realidad que, en última instancia, evidencia que la meritocracia, como ideal moderno que considera que cada individuo ocupa la posición que merece en virtud de la calidad de su talento o esfuerzo, postula un modelo de división social entre ganadores y perdedores incapaz de casar con valores como la solidaridad, la cohesión y el bien común.

\section{Conclusiones: mirando al futuro}

Como se ha visto, la Educación Ambiental más que una parte del proceso educativo es una dimensión inherente al proceso educativo entendido como un todo, que debe apelar a una crítica de los modelos de producción para permitir que las nuevas generaciones se empoderen, configurando una democracia real con un modelo de consumo que aúne el disfrute y la satisfacción de nuestras necesidades básicas con las del planeta, y permita una existencia segura y decente de la humanidad. Una tarea que no es fácil, pero de la que todos tenemos que ser partícipes, en aras de una ética universal que supere las limitaciones de fronteras o líneas divisorias y que, conforme a los derechos humanos, permita el adecuado equilibrio entre la dimensión individual y la colectiva.

Como docentes, tenemos la obligación de situar estas necesidades en el marco de un planeta que se pertenece -más que pertenecer a- para aceptar plenamente que 
formamos parte de una diversidad de pueblos, culturas e identidades que pueden y deben convivir en respeto con su entorno. En este sentido, se ha presentado un esbozo teórico de las posibilidades del ecofeminismo como movimiento de justicia ecológica que analiza el problema de la crisis ambiental en un amplio espectro que no solo abarca la normalización de la violencia con la naturaleza, sino también la articulación del sistema de género y los derechos humanos.

Por último, la crisis del coronavirus ha mostrado una depuración momentánea de la atmósfera o una mejoría la calidad de las aguas marinas. Sin embargo, los impactos que puede tener sobre el medio ambiente, el cambio climático y el $\mathrm{CO}_{2}$ a medio y a largo plazo serán muy limitados, por lo que avanzar en una educación crítica sigue siendo fundamental. La vuelta a la situación previa al confinamiento ante el lastre social y económico que acarrea la crisis epidemiológica se avecina inmediata. Todas las reflexiones vertidas en el confinamiento, la evidencia de que es posible "parar", consumir menos, reducir la movilidad, vivir de manera comunitaria, promover la empatía y luchar por políticas sociales para hacer del mundo un lugar más justo, permitirán un cambio personal y social o generarán un efecto rebote, tal y como avecinan la dialéctica de nuevos miedos. Mientras la realidad sea como es y no como debería ser, la decisión seguirá estando en nosotros: actuar o dejar que el escepticismo capitalista nos devore.

\section{Referencias}

Arrighi, G. (2007). La globalización, la soberanía estatal y la interminable acumulación de capital, F. López Castellano (Coord.), Desarrollo: crónica de un desafío permanente, (pp. 183-216). Serv. Publicaciones de la Universidad de Granada.

Baigorri, A. J., \& Caballero, M. (2018). Negacionismo, políticas demoscópicas y currículum de fracasos. El caso del cambio climático en España. Aposta. Revista de Ciencias Sociales, (77), 8-58.

Bast, J. L. (2010). Seven theories of climate change. Heartland Institute.

Bendfeldt, J. F. (1996). Ecohisteria y sentido común: respuestas del buen sentido y de la ciencia al catastrofismo ambientalista. CEES.

Benería, L. (1999). El debate inconcluso sobre el trabajo no remunerado. Revista internacional del trabajo, 118(3), 321-346.

Bieler, A., Haluza-Delay, R., Dale, A., \& McKenzie, M. (2018). A National Overview of Climate Change Education Policy: Policy Coherence between Subnational Climate and Education Policies in Canada (K-12). Journal of Education for Sustainable Development, 11(2), 63-85. https://doi.org/10.1177/0973408218754625

Björnberg, K. E., Karlsson, M., Gilek, M., \& Hansson, S. O. (2017). Climate and environmental science denial: A review of the scientific literature published in 1990-2015. Journal of Cleaner Production, (167), 229-241. https://doi.org/10.1016/j.jclepro.2017.08.066

Bliuc, A. M., McGarty, C., Thomas, E. F., Lala, G., Berndsen, M., \& Misajon, R. (2015). Public division about climate change rooted in conflicting socio-political 
identities. Nature Climate Change, 5(3), 226-229. https://doi.org/10.1038/nclimate2507

Boff, L. (2004). Ética y Moral. La búsqueda de los fundamentos. Sal Terrae.

Bohr, J. (2016). The 'climatism' cartel: why climate change deniers oppose marketbased mitigation policy. Environmental Politics, 25(5), 812-830. https://doi.org/10.1080/09644016.2016.1156106

Boussalis, C., \& Coan. T. G. (2016). Text-mining the signals of climate change doubt. Global Environmental Change, 89-100. https://doi.org/10.1016/j.gloenvcha.2015.12.001

Boykoff, M. T. (2013). Public enemy n. 1? Understanding media representations of outlier views on climate change. American behavioral scientist, 57(6), 796-817. https://doi.org/10.1177/0002764213476846

Brand. K.W. (2010). Social Practices and Sustainable Consumption: Benefits and Limitations of a New Theoretical Approach. M. Groß, \& H. Heinrichs (Eds.), Environmental Sociology. European Perspectives and Interdisciplinary Challenges, (pp. 217-235). Springer, Dordrecht. https://doi.org/10.1007/97890-481-8730-0

Brulle, R. J. (2014). Institutionalizing delay: foundation funding and the creation of U.S. climate change counter-movement organizations. Climatic Change, (122), 681-694. https://doi.org/10.1007/s10584-013-1018-7

Bryant, R. L., \& Bailey, S. (1997). Third world political ecology. Psychology Press.

Collomb, J. D. (2014). The Ideology of Climate Change Denial in the United States. European Journal of American Studies, 9(1). https://doi.org/10.4000/ejas.10305

Christensen, P. (1997). Different lifestyles and their impact on the environment. Sustainable Development, (5), 30-35.

Dunlap, R. E., \& McCright, A. M. (2010). 14 Climate change denial: sources, actors and strategies. Routledge handbook of climate change and society, 240-259. https://doi.org/10.4324/9780203876213

Dunlap, R. E., \& McCright, A. M. (2011). Organized climate change denial. J. S. Dryzek, R. B. Norgaard, \& D. Schlosberg (Eds.), The Oxford handbook of climate change and society, (1),

144-160. http://doi.org/10.1093/oxfordhb/9780199566600.003.0010

Enthoven, R. (2019). Nouvelles morales provisoires. Éd. l'Observatoire.

Etxebarria, G. (2004). Ayn Rand y los fundamentos morales del liberalismo. Cuadernos de pensamiento político FAES, (4), 187-198.

Farrell, J. (2016). Corporate funding and ideological polarization about climate change. PNAS, 113(1), 92-97. https://doi.org/10.1073/pnas.1509433112

Ferrater Mora, J. (1979). Diccionario de Filosofía. Tomo I. (Sexta ed.) Alianza Editorial.

Finch, J. (1989). Family Obligations and Social Change. Polity Press.

Freire, P. (2012). Cartas a quien pretende enseñar. Biblioteca Nueva S.L. 
Fromm, E. (2013). ¿Tener o ser? Fondo de Cultura económica de España.

Hatten-Flisher, J., \& Martusewicz, R. A. (2018). Ecofeminism and education. G. Noblit, (Ed.), Oxford Research Encyclopedia of Education. Oxford University Press.

Jandrić, P., Jaldemark, J., Hurley, Z., Bartram, B., Matthews, A., Jopling, M., \& Tesar, M. (2020). Philosophy of education in a new key: Who remembers Greta Thunberg? Education and environment after the coronavirus. Educational Philosophy and Theory, 1-21. https://doi.org/10.1080/00131857.2020.1811678

Jensen, B. B., \& Schnack, K. (2006). The Action Competence Approach. Environmental Education Research 12(3-4), 471-486. https://doi.org/10.1080/13504620600943053

Jickling, B. (2013). Normalizing Catastrophe: An Educational Response. Environmental Education Research, 19(2), 161-176. https://doi.org/10.1080/13504622.2012.721114

Krasny, M. E., \& DuBois, B. (2019). Climate adaptation education: embracing reality or abandoning environmental values. Environmental Education Research, 25(6), 883-894. https://doi.org/10.1080/13504622.2016.1196345

Latour, B. (2017). Cara a cara con el planeta. Una nueva mirada sobre el cambio climático alejada de las posiciones apocalípticas. Siglo XXI Editores.

Laursen, J. Ch. (2009). Escepticismo y política. Revista de Estudios Políticos (144), 123 142.

Li, H. L. (2007). Ecofeminism as a pedagogical project: Women, nature, and education. Educational Theory, 57(3), 351-368. https://doi.org/10.1111/j.17415446.2007.00262.x

Lomborg, B. (2004). Global crises, global solutions. Cambridge University Press.

Martusewicz, R. A., Edmundson, J., \& Lupinacci, J. (2015). EcoJustice education: Toward diverse, democratic, and sustainable communities. (2nd ed.). Routledge.

McCarthy, T. (1992). Ideales e Ilusiones. Tecnos.

McCright, A. M. y Dunlap, R. E. (2010). Anti-reflexivity. Theory, Culture \& Society, 27(23), 100-133. https://doi.org/10.1177/0263276409356001

McCright, A. M., \& Dunlap, R. E. (2011). The politicization of climate change and polarization in the American public's views of global warming, 2001-2010. The Sociological Quarterly, 52(2), 155-194. https://doi.org/10.1111/j.15338525.2011.01198.x

Meadows, D., Meadows, D., Randers, J., \& Behrens III, W. W. (1972). The Limits to Growth. Potomac Associates - Universe Books.

Mendivelso, J. C., \& Arias, I. M. (2015). El Antropoceno: aportes para la comprensión del cambio global.Ar@cne: revista electrónica de recursos en internet sobre geografía y ciencias sociales, 1-20

Merchant, C. (1983). The Death of Nature: Women, Ecology, and the Scientific Revolution. New York: Harper Collins. 
Mérida Donoso, J. A. (2019). Concienciar en ecología. La labor del docente en ciencias sociales, Revista Aula, (286), 9.

Mérida Donoso, J. A. (2018). El otro Brasil, la violencia por la tierra: un recorrido histórico. Anales de la Fundación Joaquín Costa, (30), 57-158.

Morín, E. (2010). ¿Hacia el abismo? Globalización en el siglo XXI. Paidós.

Niño, A. C. M., \& Romero, J. F. H. (2014). La formación ambiental en la educación superior: una revisión necesaria. Revista Luna Azul, (39), 186-206.

Osborn. F. (1948). Our plundered planet. Little, Brown \& Co.

Phillips, M., \& Rumens, N. (2016). Contemporary Perspectives on Ecofeminism. New York/London: Routledge.

Prebisch, R. (1988). Dependencia, interdependencia y desarrollo. Revista de la CEPAL, (34), 205-212.

Roitman Rosenmann, M. (2005). Las razones de la democracia en América Latina. Siglo XXI.

Roque, M. (2003). Una concepción educativa para el desarrollo de la cultura ambiental desde una perspectiva cubana. IV Congreso Iberoamericano de Educación Ambiental, (pp. 1-29) celebrado en La Habana, Cuba, del 2 al 6 de junio de 2003.

Sacristán Luzón, M. (2009). Pacifismo, ecología y política alternativa. Sol 90.

Sandel, M. J. (2020) La tiranía del mérito: ¿Qué ha sido del bien común? Debate.

Sauer, C. O. (1956). La gestión del hombre en la tierra. Conferencia ofrecida en el Simposio El Papel del Hombre en el Cambio de la Faz de la Tierra. Princeton.

Schmelkes, S. (2002). La enseñanza de la lectura y la escritura en contextos multiculturales. Trabajo presentado en el VII Congreso latinoamericano para el desarrollo de la lectura y la escritura, (pp. 1-16), celebrado en Puebla, México, del 16 al 19 de octubre de 2002.

Stevenson, R. B. (2007). Schooling and Environmental Education: Contradictions in Purpose and Practice. Environmental Education Research 13(2), 139-153. http://dx.doi.org/10.1080/13504620701295726

Tilbury, D., \& Mulà, I. (2009). Review of education for sustainable development policies from a cultural diversity and intercultural dialogue: Gaps and opportunities for future action.

UNESCO. https://unesdoc.unesco.org/images/0019/001901/190101E.pdf

Toro, D. R. (2006). Ecología, ecologismo y medio ambiente. Revista Luna Azul, 1(1), 1-4.

Turner, R. (2015). Teaching for EcoJustice: Curriculum and lessons for secondary and college classrooms. Routledge. 